\title{
VOLTAGE STABILITY OF ELECTRICAL POWER NETWORKS WITH HIGH PENETRATION LEVEL OF WIND GENERATION
}

\author{
Salwa M. El-Samanoudy*1, El-Said Osman ${ }^{2}$, Mohamed I. El-Said ${ }^{2}$ \\ and Mohamed K. El-Shaer ${ }^{2}$ \\ ${ }^{1}$ Egyptian Electricity Holding Company, Cairo, Egypt ${ }^{1}$, \\ ${ }^{2}$ Department of Electrical Engineering, faculty of Engineering, Al Azhar University, \\ Cairo, Egypt \\ *Corresponding Author E-mail: salwa_elsamanoudy@yahoo.com
}

\begin{abstract}
Voltage instability is considered as one of the main threats to secure operation of power system networks around the world. Nowadays, Integration of large-scale wind power may have severe impacts on the power system operation. Stable, reliable and economic operation of the power system under the massive integration of wind power is a big challenge to power system operators. This paper scrutinizes to study the voltage stability problems for the integration of wind power to the IEEE-39 bus-systems.
\end{abstract}

The main objective of this study is to analyze the voltage stability of the IEEE-39 bus networks with large-scale wind power under normal operation using PV and QV analyses. As one of the classic static Voltage stability assessment (VSA) method, the P-V curve is widely used in identifying the weak buses in one power system. Normally, there is a required range of bus voltage variation that restricts load with fixed power factor within a maximum value. The loading margin can be defined as the distance between the operating point and the maximum load. These steady-state methods, which inherently require less computational capability, can indicate the level of stability of a power system. Therefore, QV curves analysis tools are used in this paper.

The importance of accurate representation of the reactive power capabilities of wind generators in voltage stability studies was emphasized in the analyses. These analyses define the amount of reactive power required to enhance voltage stability and hence can be improved by adding suitable reactive power compensator. Here STATCOM is used as a reactive power compensator. Simulation of the 39 bus-IEEE network with integrated wind generators are developed using PSS/E software.

\section{KEYWORDS: Voltage Stability, P-V Analysis, Q-V Analysis, Doubly-Fed Induction Generator (DFIG), Reactive Power Capabilities, Reactive Compensator (STATCOM)}



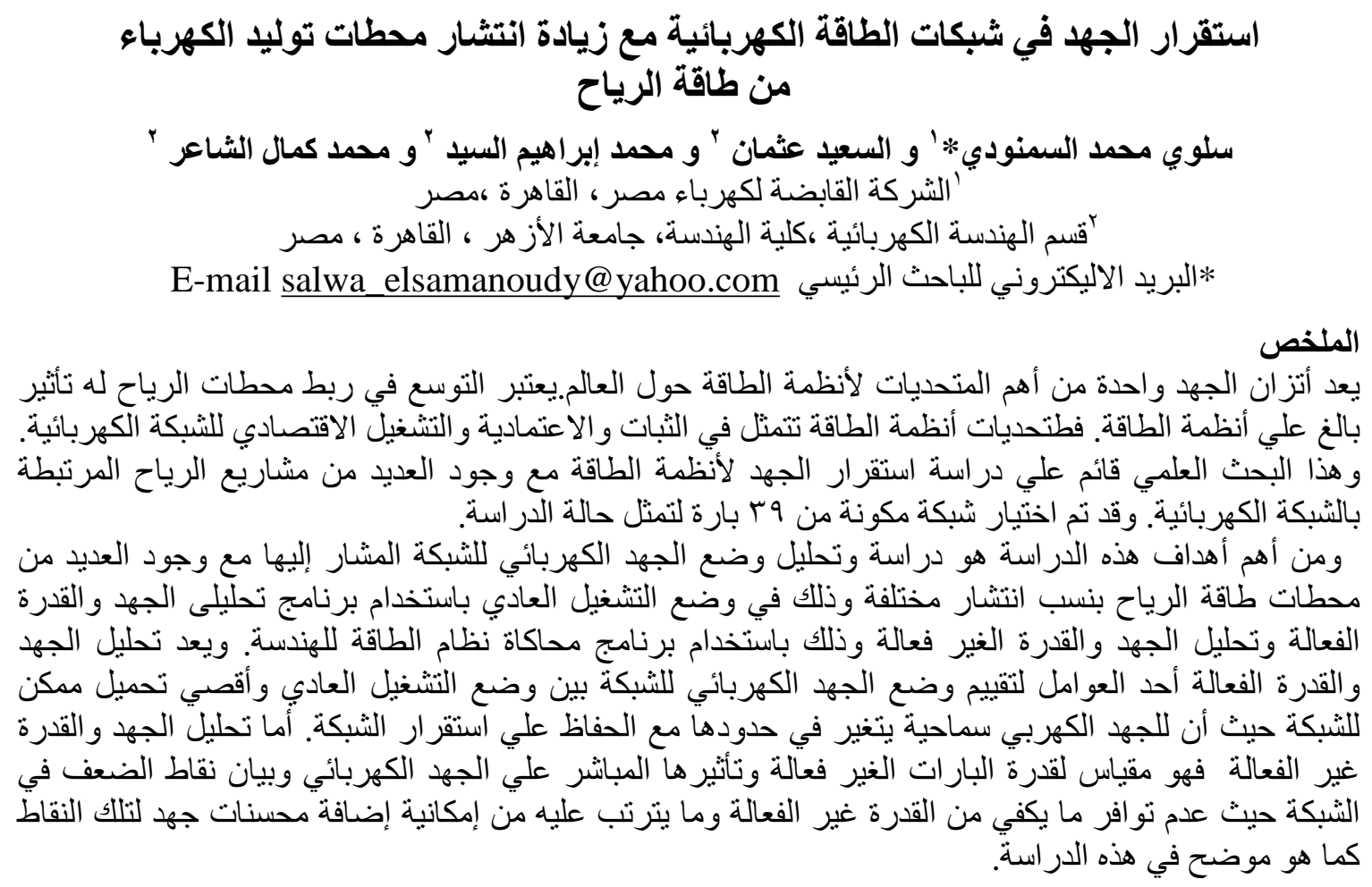
الكلمات المفتاحية: أتزان الجهد، تحليل الجها والقدرة الفعالة ، تحليل الجهـ والقدرة غير الفعالة، مولد حث ثنائي

\section{INTRODUCTION}

Utilization of renewable energy comes from the perspective of environmental conservation and fossil fuel shortage. Recent studies suggest that in medium and long terms, doubly fed-induction generator (WT 3) and full-size-converter generator (WT4) models will become commercially so attractive that large-scale implementation of this type can be seen in many parts of the world [1-4]. The integration of these energy sources into the existing power systems is one of the main challenges due to the major concerns about the power system stability as well as system reliability. In the power system environment, the voltage stability is one of the main indicators of the power system stability [5], [6]. It has been proved that inadequate reactive power compensation during stressed operating condition can lead to voltage instability. Although large-scale WT 3 and WT 4 are capable of generating reactive power, yet reactive power generation capability of these types are limited by grid code and normally work very close to the unity power factor (usually operate 0.95 lead lag power factor) [2], [7]. However, the size and position of large wind turbines can introduce significant impact on power system voltage stability as the level of wind penetration become a relevant percentage of total installed power. Thus, this paper assesses the impact of large-scale wind generation on power system voltage stability. The case studies are presented in the paper based on IEEE- 39 bus test system. Different wind penetration levels $(10 \%, 20 \%$ and $50 \%)$ of the total installed capacity have been considered for the assessment of system voltage stability and these are: The rest of the paper is divided into four sections; first section demonstrates the modeling of wind farm. The voltage stability analysis is presented in the second section. The third section shows the simulation results, the main conclusions is illustrated in last section.

\section{SYSTEM MODELING}

PSS/E program is used to develop the wind farms and PV generator models for simulation. It supports all types of the available wind turbines, which are split into several types, as follows:

Type 1: Direct connected Conventional Induction Generator 
Type 2: Wound rotor Induction Generator with Variable Rotor Resistance

Type 3: Doubly-Fed Induction Generator DFIG

Type 4: Full Size Converter Unit

Generic Wind Models are designed to be used in studies related to the integration of Wind Turbine Generators (WTG) in an Electrical Power System. The Generic model (WT3) is studied in this paper.

\section{WIND TURBINE GENERATOR}

The energy conversion of most modern wind turbines can be divided into fixed speed or variable speed. The squirrel cage induction generator (SCIG) is the main type of generator used in a fixed speed unit. The doubly-fed induction generator (DFIG) is the main type of generator used in a variable speed unit, which is connected to the grid using power-electronic converter technology. For the studies carried out in this paper, we focused on a DFIG variable- speed unit modeled as a PV bus.

The Doubly - Fed Induction Generator (DFIG) is a variable speed wind turbine. The rotor winding is fed using a back-to-back voltage source converter. The wind turbine rotor is connected, also, to the generator through a gearbox as shown in Figure 1. At high wind speeds, the power extracted from the wind is limited by pitching the rotor blades. This type of wind generator is one of the preferred technologies in wind generation applications since it supports a wide range of wind speed operations. The typical variable speed range is $30 \%$ more than the synchronous speed [8]. In addition, it provides an effective control of the wind generator's active and reactive powers through using backto back converters. Furthermore, the power converter system can perform as reactive power compensation and voltage support for the grid [9]. Also, the DFIG type of generator has advantages at reducing mechanical stress and optimizing power capture.

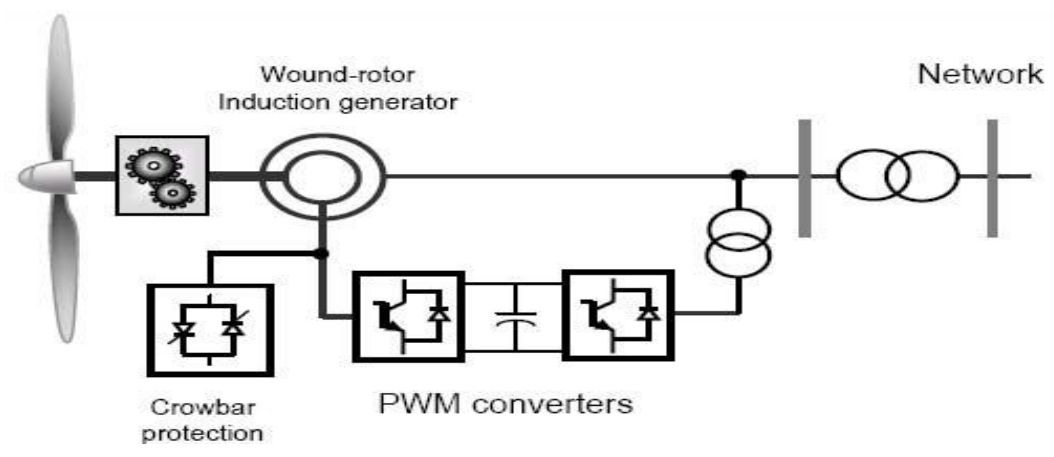

Figure (1) Doubly-Fed Induction Generator

\section{VOLTAGE STABILITY ANALYSIS}

Voltage stability is the ability of a power system to maintain steady voltages of all buses in the system after being subjected to a disturbance [2]. Modern analytical tools are used for voltage stability analysis such as Power -Voltage (PV curve) and Reactive-Voltage (QV curve). PV and QV analyses are demonstrated in this paper. These analyses monitor voltage and loading conditions and stores the results in a binary file. Subsequently, this file can be processed to produce a variety of reports of voltage violations, loadings and available capacity.

\subsection{PV Analysis}

When considering voltage stability, the relationship between transmitted power $(\mathrm{P})$ and receiving end voltage $(\mathrm{V})$ is of interest. The voltage stability analysis process involves the transfer of $\mathrm{P}$ from one region of a system to another, and monitoring the effects to system voltages, V. This type of analysis is commonly referred to the PV study. Using continuation power flow (CPF) or standard power flow algorithm, the load demand is increased incrementally, and the demand in MW and the bus voltage of focus are reported for the generation of the PV curve, Figure 2. The PV curve is analyzed to identify the nose point or the voltage collapse point. The impact of a disturbance or 
reactive power compensation can be evaluated by looking at a PV curve as shown in Figure 2. Details of PV methodology are given in bibliography [5], [10].

\subsection{QV Analysis}

Voltage stability depends on how the variations in the reactive power $(\mathrm{Q})$ and the active power (P) affect the voltages at the load buses. The influence of reactive power characteristics of devices at the receiving end is more apparent in a QV relationship. It shows the sensitivity and variation of bus voltages with respect to reactive power injections or absorptions. Reactive power margin or deficit can be determined by generating the VQ graph. The independent variable, bus voltage, is varied to compute the MVAr requirement, which is the dependent variable. A dummy synchronous condenser is used for MVAr generation at the bus of concern, as shown in Figure 3. Standards [5], [10], provide details of the procedure for this area of static voltage stability.

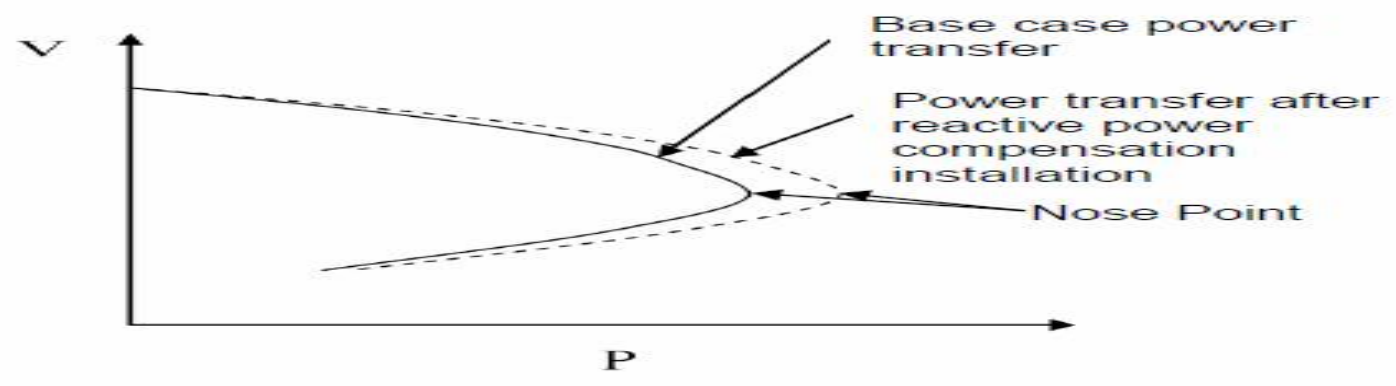

Figure (2) Power-Voltage Curve for Static Voltage Stability

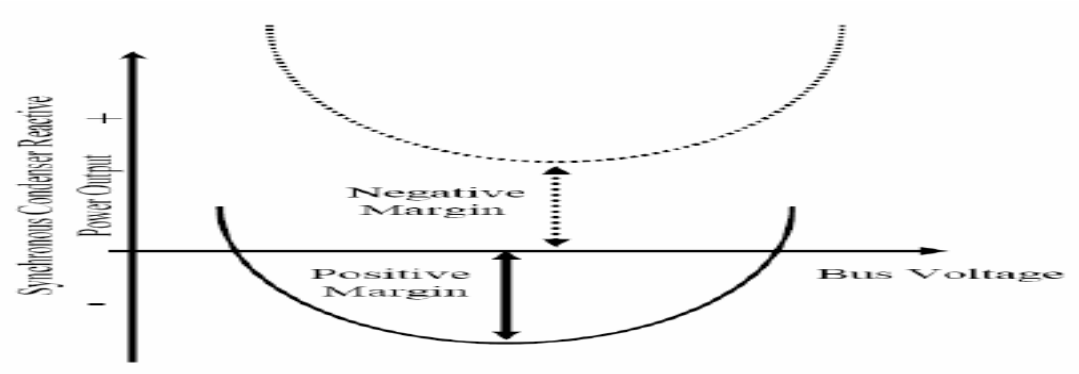

Figure (3) Voltage-MVAr (VQ) curve for Static Voltage Stability

\section{CASE STUDIED}

The analytical tools that are described in the previous section was applied to IEEE $39-$ bus as a benchmark with grid connected wind farm. PSS/E program [10] is used to perform the presented simulations.

\section{9- Bus System Description}

IEEE 39-bus network consists of ten synchronous generators. Buses from 30 and 39 consist with a total generating capacity of 5917 MW and 2833 MVAR. The technical data of the IEEE 39-bus is found in [12]. The wind generators are doubly fed induction generators (DFIGs). The DFIG was modeled as a PV bus with reactive power generator limits enforced. Each DFIG generator is operated such that to maintain its terminal voltage at $1.0 \mathrm{p}$.u, without exceeding its reactive power capability with 0.95 power factor leading or lagging. The total loads of the network are 5856.8 MW and 2780.6 MVAR base load data of the network. Aggregation model is used to develop the wind farms. The penetration levels of these generators to investigate the performance of this model, four scenarios are studied as follows:

Scenario 1: 39 bus test system with $10 \%$ wind penetration.

Scenario 2: 39 bus test system with $20 \%$ wind penetration at buses number 6,7 .

Scenario 3: 39 bus test system with $50 \%$ wind penetration at buses number 4,5,6,7. 
Scenario 4: 39 bus test system with $20 \%$ wind penetration at buses number 6,7 and 50 MVAR STATCOM.

The simulation will be processed under different penetration levels of wind generation as shown in Table 1. This paper analyses the impact of the wind power on steady state voltage stability using PV and QV analyses and on total real power loss.

Table (1) Different wind penetration levels and different locations

\begin{tabular}{|c|c|}
\hline Case & IEEE 39 Bus System \\
\hline $10 \%$ wind penetration & $10 \%(600 \mathrm{MW})$ \\
\hline $20 \%$ wind penetration & $20 \%(1200 \mathrm{MW})$ \\
\hline $50 \%$ wind penetration & $50 \%(3000 \mathrm{MW})$ \\
\hline
\end{tabular}

\section{RESULTS AND DISCUSSION}

The PV and QV results are obtained for the base cases with all elements in service. The simulation results are divided into two sections. In the first section, the system voltage stability was investigated by using P-V curves with different wind penetration levels. In the second section, total real power loss was investigated with different wind penetration levels. Bus voltages are monitored below 0.95 p.u. or above 1.05 p.u. for the normal conditions and different wind penetration levels.

\subsection{System voltage stability with different wind penetration levels}

In order to assess the impact of wind generation on the voltage stability, we studied two scenarios of the described wind generation connections with different penetration levels and compared these results with the base case without any addition of wind generation. In this study, the DFIG was modeled as a PV bus with Q limits applied. The P-V curve was analyzed to identify the collapse margin or voltage collapse point. The collapse margin measured the distance from the current operating point to the maximum loading in the PV curve.

Figure 4 illustrates the impact of different wind penetration levels on the voltage stability of the IEEE 39 bus-system where bus 7's P-V curve of different wind penetration levels of the IEEE 39 bus system, compared to the base case when no wind generators were connected to the system. As shown, the system collapse margin was $1000 \mathrm{MW}$ for the base case and for $10 \%$ penetration level of wind generations at bus 7 . The system collapse margin decreased to $631.25 \mathrm{MW}$ when the percentage of wind capacity was $20 \%$ $(1200 \mathrm{MW})$ and $50 \%$ (3000 MW). It meant that a higher wind penetration might weaken the system voltage stability. Table 2 shows the summary results.

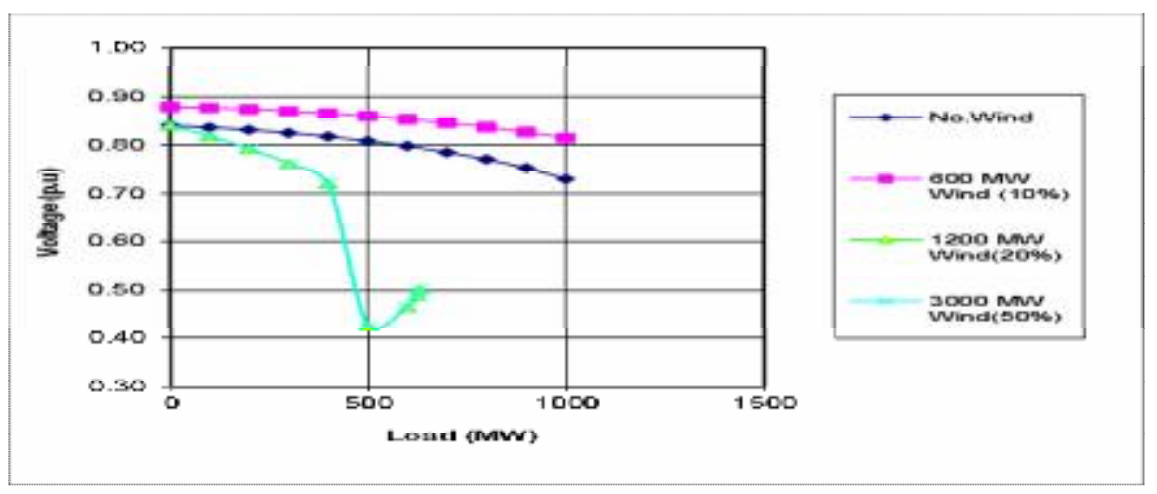

Figure (4) PV curve analysis of IEEE 39 bus-system for the base case and different wind penetration 
Table (2) PV curve Result summary when wind farms located at different location to IEEE 39 buses

\begin{tabular}{|c|c|c|c|}
\hline $\begin{array}{c}\text { Wind Penetration } \\
\text { Level }\end{array}$ & $\begin{array}{c}\text { Location of wind } \\
\text { farms }\end{array}$ & $\begin{array}{c}\text { Critical Voltage } \\
\text { p.u }\end{array}$ & $\begin{array}{c}\text { Collapse Margin } \\
\text { MW }\end{array}$ \\
\hline No wind 0\% & ÜÜÜÜ & 0.73 & 1000 \\
\hline $10 \%(600 \mathrm{MW})$ & Bus 7 & 0.82 & 1000 \\
\hline $20 \%(1200 \mathrm{MW})$ & Buses 6,7 & 0.49 & 631 \\
\hline $50 \%(3000 \mathrm{MW})$ & Buses 4,5,6,7 & 0.49 & 631 \\
\hline
\end{tabular}

For IEEE 39 bus system, wind farms were connected to buses which need suitable reactive power support depending on QV analysis results. This result shows the reactive power capability for each bus as shown in Table3. All these results lead to a conclusion that the high penetration level of wind generation will affect severely the system voltage stability.

Table (3) QV curve Result summary when wind farms located at different location to IEEE 39 buses

\begin{tabular}{|c|c|c|}
\hline $\begin{array}{c}\text { IEEE bus } \\
\text { system }\end{array}$ & Bus Number & $\begin{array}{c}\text { The needed reactive } \\
\text { power (MVAR) }\end{array}$ \\
\hline 39 bus system & 7 & 770.5 \\
\hline 39 bus system & 6 & 686.5 \\
\hline
\end{tabular}

\subsection{Impact of wind generation on real power losses}

This section investigates the system's total real power losses with different wind penetration levels. The investigation was conducted to demonstrate the effect on system real power losses from two different aspects, which are the level of wind generation (i.e., $10 \%$ to $50 \%$ ) and the dispersion of wind generation (i.e., 1 or 2 or 4 locations) along the system. The wind generation was varied from $10 \%$ to $50 \%$ of the total network installed generation; the total system real losses were recorded for the 39 IEEE bus system.

Figures 5 show the impact of different wind penetration level combinations and the dispersion effect of wind generation on system real power losses. The total system real losses without wind generation and with different penetration levels of wind generation. In Figure 5, it is observed that when the wind penetration level increased to 10\%, the total system real losses decrease. However, the cases of $20 \%$ and $50 \%$ wind penetration, the total system real losses remain the same as the base case without wind generation. Hence the high penetration level of wind has a bit effect on the total real power losses.

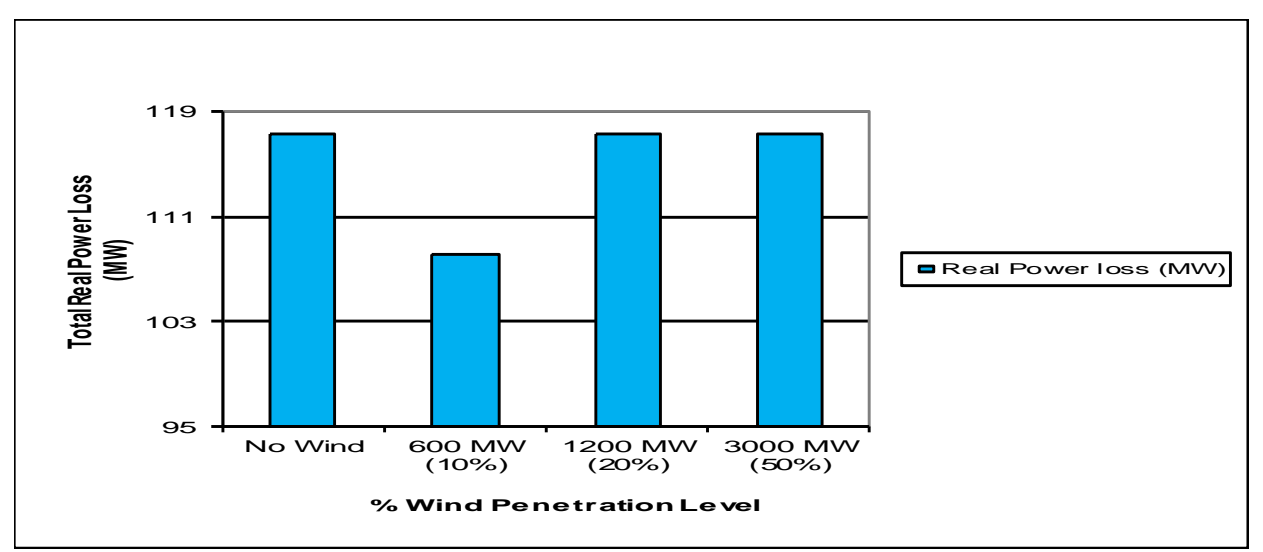

Figure (5) Total real power losses of the 39-bus system without and with different wind penetration Levels at different locations 


\subsection{Scenario 4 with a Reactive Compensator (STATCOM) in the two IEEE bus systems}

In this section, 50MVAR STATCOM added to bus 7 in IEEE 39 bus-System; where bus bus 7 in IEEE 39 have shortage in the needed reactive power to reach 1p.u. voltage.

STATCOM is a static synchronous compensator used to improve the performance of the grid connected with wind generators [13]. Figure 6 shows a comparison between case 2 and case 4 as STATCOM maintain voltage 1 p.u. along different loading till the point of breakdown.

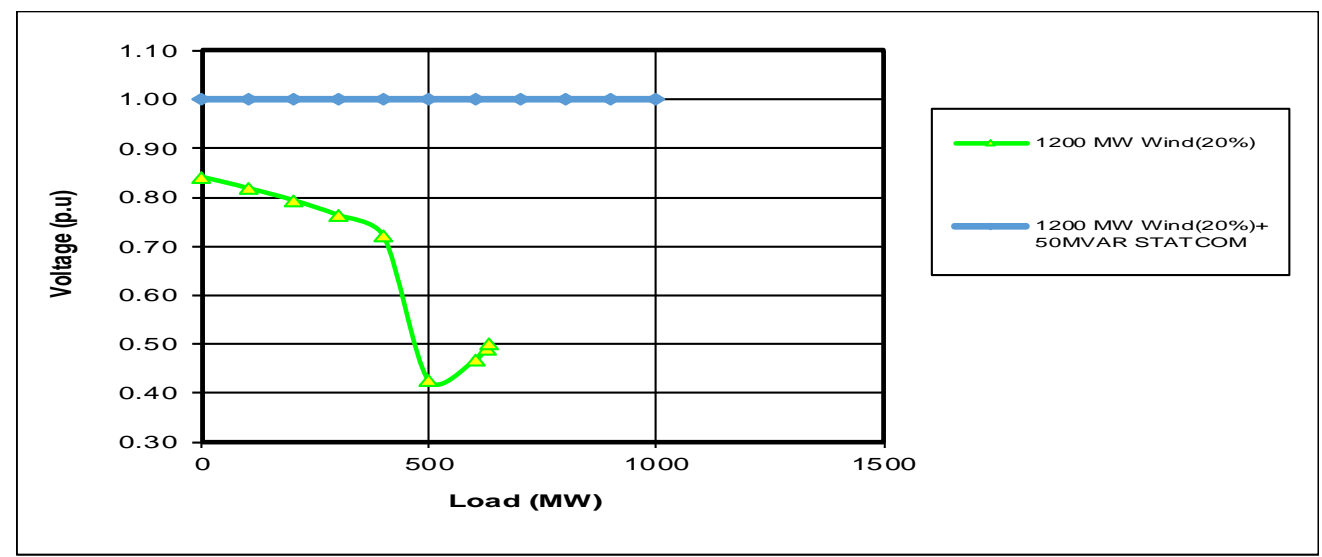

Figure (6) PV curve analysis of IEEE 39 bus-system for $20 \%$ wind at bus 39 and $20 \%$ wind at bus 7 +50 MVAR STATCOM at bus 7

Figure 7 shows the effect of adding STATCOM on the real power losses. The active power loss is reduced significantly.

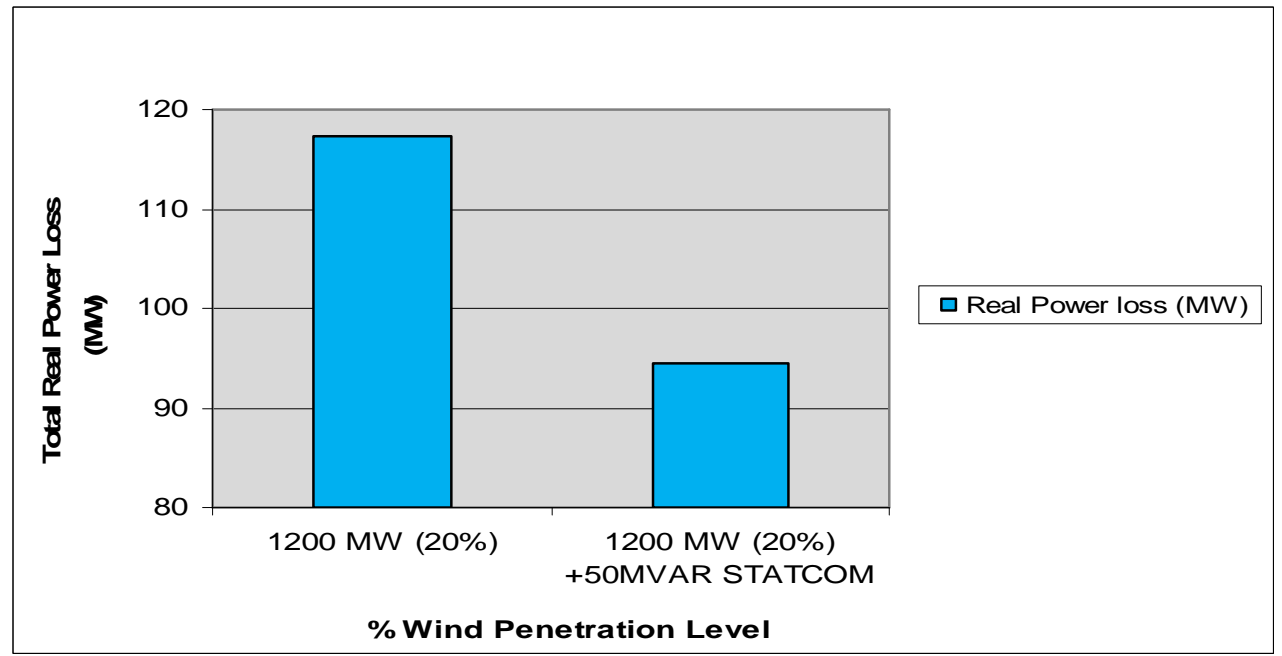

Figure (7) Total real power losses of the 39-bus system without and with STATCOM at bus 7.

\section{CONCLUSIONS}

From the previous analysis, the impact of different wind penetration levels and dispersion of wind farms on the power transmission network; on the voltage stability and on the real power losses. A DFIG wind farm with voltage-controlled mode integrated into the IEEE 39 buses system where the connections of wind farms were considered for three different penetration levels. 


\section{From the results presented in this paper, the following can be concluded:}

1. Higher penetration levels more than twenty percent did not improve the voltage collapse margin in the most of the studied cases and had a negative effect on voltage stability of the network. Although, the penetration levels of wind generation up to twenty percent improve the voltage collapse margin of transmission system, which mean that higher wind penetration might weaken the system voltage stability.

2. Also, the analysed results in this paper show that the wind penetration levels are able to reduce the real losses or remain them as the base case without wind farms addition.

3. The Location of wind farm should be closer to load areas to support the surrounding buses with the needed real and reactive power.

4. Adding STATCOM has a great effect in enhancing both voltage stability and real power losses to achieve a reliable and sustainable grid.

5. In future work, we intend to elaborate meticulously on each factor and every single parameter that has a role on the upper limit of wind level penetration.

6. Thoroughly investigate how each factor and each parameter contributes to that upper limit of wind penetration level. At the end, it is desirable to be in a position of controlling the entire voltage stability issue.

\section{REFERENCES:}

1. Annual Market, (Update 2017). Global Wind Report, Global Wind Energy Council.

2. Y. Chi, Y. Liu, W. Wang and H. Dai. (22- 26 October 2006). "Voltage Stability Analysis of Wind Farm Integration into Transmission Network," International Conference on Power System Technology, Power Congress (2006), Pages (1-7).

3. E. Camm and C. Edwards, (21-24 April 2008). "Reactive Compensation Systems for Large Wind Farms," IEEE/PES Transmission and Distribution Conference and Exposition, Pages (1-5).

4. P. Kundur, J. Paserba, V. Ajjarapu, G. Andersson, A. Bose, C. Canizares, N. Hatziargyriou, D. Hill, A. Stankovic, C. Taylor, T. Van Cutsem, and V. Vittal , (2004). "Definition and classification of power system stability IEEE/CIGRE joint task force on stability terms and definitions," Power Systems, IEEE Transactions on Power Systems, Volume (19), Pages (1387-1401).

5. C.W. Taylor, (1994). "Power System Voltage Stability", EPRI Power Engineering Series, McGraw-Hill.

6. P. Kundur, (1994). "Power System Stability and Control", McGraw-Hill.

7. Prabha Kundur, John Paserba, Venkat Ajjarapu, Goran Andersson, Anjan Bose, Claudio Canizaes, etc, (2004). Definition and Classification of Power system , IEEE transaction on Power systems, Volume (19), Pages (14 -1387)

8. S. Muller, M. Deicke and Rik W. De Doncker, (May/June 2002). "Doubly Fed Induction Generator systems for Wind Turbines", IEEE Industry and Applications Magazine, Pages (26-33).

9. Guide to WECC/NERC Planning Standards, (March 30, 2006). I.D: "Voltage Support and Reactive Power", Western Electricity Coordinating Council (WECC), available on line -

https://www.wecc.biz/modules.php?op=modload\&name=Downloads\&file=index\&req=view sdownload\&sid $=100$

10. GUI Users Guide, (October 2013). PSS $₫ E 33$.

11. Technical data of IEEE 14-Bus System, available on line https://www.researchgate.net/figure/Single-line-diagram-of-IEEE-14-Bus-system-in-PSSE_fig1_313422078

12. Technical data of IEEE 39-Bus System, available on line https://hvdc.ca/knowledge-base/read,article/28/ieee-39-bus-system/v:

13. K. Sree Latha and M. Vijaya Kumar, (13-15 March 2014). "STATCOM for enhancement of voltage stability of a DFIG driven wind turbine", 2014 Power and Energy Systems: Towards Sustainable Energy. 